\title{
Effects of Endothelin Family on ANP Secretion
}

\author{
Kuichang Yuan ${ }^{3 *}$, Byung Mun Park ${ }^{1 *}$, Young Tae Choi ${ }^{1 *}$, \\ Jong Hun $\mathrm{Kim}^{2}$, Kyung Woo Cho ${ }^{1}$, Suhn Hee Kim ${ }^{1}$ \\ Department of ${ }^{1}$ Physiology and ${ }^{2}$ Surgery, \\ Chonbuk National University Medical School, Jeonju 560-180, KOREA \\ ${ }^{3}$ Department of Internal Medicine, Yanbian University, China
}

Running head: Effects of ET family on ANP secretion

Enclosed Figures 5

* These authors contributed equally

Correspondence to: Suhn Hee Kim, MD, PhD

2-20 Keum-Am-Dong-San,

Department of Physiology,

Chonbuk National University Medical School,

Jeonju 561-180, Korea.

e-mail shkim@chonbuk.ac.kr

FAX 82632749892

TEL 82632703078 


\section{ABSTRACT}

The endothelins (ET) peptide family consists of ET-1, ET-2, ET-3, and sarafotoxin (s6C, a snake venom) and their actions appears to be different among isoforms. The aim of this study was to compare the secretagogue effect of ET-1 on atrial natriuretic peptide (ANP) secretion with ET-3 and evaluate its physiological meaning. Isolated nonbeating atria from male Sprague-Dawley rats were used to evaluate stretch-activated ANP secretion in response to ET-1, ET-2, ET-3, and s6C. Changes in mean blood pressure (MAP) were measured during acute injection of ET-1 and ET-3 with and without natriuretic peptide receptor-A antagonist (A71915) in anesthetized rats. Changes in atrial volume induced by increased atrial pressure from o to $1,2,4$, or $6 \mathrm{cmH}_{2} \mathrm{O}$ caused proportional increases in mechanically-stimulated extracellular fluid (ECF) translocation and stretch-activated ANP secretion. ET-1 (10 nM) augmented basal and stretch-activated ANP secretion in terms of ECF translocation, which was blocked by the pretreatment with $\mathrm{ET}_{\mathrm{A}}$ receptor antagonist $(\mathrm{BQ} 123,1 \mu \mathrm{M})$ but not by $\mathrm{ET}_{\mathrm{B}}$ receptor antagonist $(\mathrm{BQ} 788,1 \mu \mathrm{M})$. $\mathrm{ET}_{\mathrm{A}}$ receptor antagonist itself suppressed stretchactivated ANP secretion. As compared to ET-1- induced ANP secretion (3.2-fold by $10 \mathrm{nM}$ ), the secretagogue effects of ANP secretion by ET-2 was similar (2.8-fold by $10 \mathrm{nM})$ and ET-3 and s6C were less potent (1.7-fold and 1.5-fold by $100 \mathrm{nM}$, respectively). Acute injection of ET-1 or ET-3 increased mean blood pressure (MAP), which was augmented in the presence of natriuretic peptide receptor-A antagonist. Therefore, we suggest that the order of secretagogue effect of ET family on ANP secretion was ET-1 $\geq$ ET-2 > ET-3 > s6C and ET1-induced ANP secretion negatively regulates the pressor effect of ET-1.

Keywords: atrial natriuretic peptide, endothelin, stretch, atrium, receptor, blood pressure 


\section{Introduction}

The endothelins (ET) peptide family consists of 21 amino acid isoforms, ET-1, ET-2, ET3, and sarafotoxin (a snake venom). ET-2 is very similar to ET-1, while ET-3 and sarafotoxin differ from ET-1 by six and seven amino acids, respectively. ET-1 is the most abundant isoform and secreted mainly by endothelial cells. ET-2 is found in the kidney and intestine, whereas ET-3 is found in the central nervous system. ET-1 has a wide range of biological actions including vasoconstriction $[14,31]$, positive inotropic effect $[17,18]$, cellular proliferation, and control of water and sodium excretion $[1,2]$. The potency of mitogenesis [25], renovascular constriction [14], and sodium excretion [6] are reported to be different among isoforms.

On the other hands, atrial natriuretic peptide (ANP) is a cardiac peptide hormone which is involved in the regulation of blood volume and pressure $[7,8]$. The synthesis and secretion of ANP is regulated by developmental, hormonal, and hemodynamic factors [15, 29]. Atrial myocytes constitute major site of synthesis and the secretion of ANP is stimulated by atrial wall stretch $[5,9,22]$. ET-1 is well-known as one of the most potent chemicals for ANP secretion [10]. ET-1 increases ANP secretion in isolated rat cardiac myocytes $[11,12]$, in isolated rat atria $[16,28]$, and in conscious rats [13, 26]. Based on their biological functions in cellular proliferation and vascular smooth muscle, ET-1 is an antagonistic hormone to ANP. Eventhough many studies for ET-1-induced ANP secretion have been done, there are a few reports about the potency of secretagogue effect of ET-3 and sarafotoxin on ANP secretion as compared to ET-1. Therefore, the aim of the present study was to compare the secretagogue effect of ET-1 on ANP secretion with ET-3 and sarafotoxin (s6C) in isolated perfused nonbeating atria and evaluated its physiological meaning in anesthetized rats. 


\section{Materials and methods}

\subsection{Animals}

Male Sprague-Dawley rats, weighing between 230 and $250 \mathrm{~g}$, were obtained from Daehanbiolink (Eumsung, Korea) and housed in a temperature-controlled room with a 12:12$\mathrm{h}$ light-dark cycle. Animals were provided free access to standard laboratory chow (5L79 Purina rat \& mouse $18 \%$ chow, Charles River Laboratories Inc., Wilmington, MA) and water. All of experimental protocols conformed to the National Institutes of Health Guide for the Care and Use of Laboratory Animals (NIH publication No. 85-23, revised 1996) and were approved by our institution.

\subsection{Isolated perfused nonbeating atrial preparation}

Rats were sacrificed by decapitation and an isolated perfused atrial preparation was made by the method described previously [19]. Briefly, the heart was rapidly removed, placed in oxygenated saline and both atria were separately dissected from the heart. A Tygon cannula containing three small catheters sealed within it was inserted into the atrium and secured by ligatures. The cannulated atria were transferred, fitted into the organ chamber containing buffer solution $\left(36.5^{\circ} \mathrm{C}\right)$ and fixed with water-tight silicone rubber cap. The atrium was immediately perfused with oxygenated HEPES buffer solution at a rate of $0.4 \mathrm{ml} / \mathrm{min}$ with peristatic pump. The composition of the buffer solution was as follows: $\mathrm{NaCl} 118$, $\mathrm{KCl} 4.7, \mathrm{CaCl}_{2} 2.5, \mathrm{MgSO}_{4}$ 1.2, $\mathrm{NaHCO}_{3} 25$, HEPES 10, glucose $10 \mathrm{mM}$ and bovine serum albumin (BSA) $0.1 \%$. The pericardial buffer solution which contained $\left[{ }^{3} \mathrm{H}\right]$-inulin to measure the translocation of extracellular fluid (ECF) was also oxygenated by silicone tubing coils located inside the organ chamber. The pericardial space of organ chamber was sealed and connected with a calibrated microcapillary tube, by which changes in atrial volume were 
monitored. The atrium was perfused for $30 \mathrm{~min}$ to stabilize the secretion of ANP and to maintain the $\left[{ }^{3} \mathrm{H}\right]$-inulin level in the extracellular space at a steady-state. The perfusate was collected every 2 min interval at $4^{\circ} \mathrm{C}$. After two collection periods, atrial distension was induced for $2 \mathrm{~min}$ by elevating the position of out-flow catheter tip to $1 \mathrm{cmH}_{2} \mathrm{O}$ and atrial contraction was induced by lowering the position of the catheter tip to the basal level. Atrial pressure was subsequently increased from 0 to $1,2,4$, and $6 \mathrm{cmH}_{2} \mathrm{O}$ for 2 min at every 8 min. After finish experiments, atrial wet weight was measured.

\subsection{Experimental groups}

Experiments were conducted with 11 groups. Group 1 included control atria perfused with HEPES buffer $(\mathrm{n}=7)$. Group 2 included ET-1 (human, porcine, dog, rat form) -perfused atria (Bachem AG, Bubendorf, Switzerland;10 nM, n = 8) [20]. Group 3 and 4 included ET-1perfused atria in the presence of $\mathrm{ET}_{\mathrm{A}}$ receptor competitive inhibitor, cyclo (D-Asp-Pro-DVal-Leu-D-Trp, (BQ123; Bachem AG; $1 \mu \mathrm{M}, \mathrm{n}=8$ ) and $\mathrm{ET}_{\mathrm{B}}$ receptor antagonist, BQ788 (Bachem AG ; $1 \mu \mathrm{M}, \mathrm{n}=8$ ), respectively. In group 5 and 6 , atria were perfused with BQ123 $(1 \mu \mathrm{M}, \mathrm{n}=7)$ or BQ788 $(1 \mu \mathrm{M}, \mathrm{n}=7)$ alone, respectively. In group 7 and 8 , atria were perfused with HEPES buffer containing low $\mathrm{Ca}^{2+}(25 \mu \mathrm{M})$ in the absence $(\mathrm{n}=6)$ and presence of ET-1 (10 nM, n=8), respectively. Group 9 included ET-2 -perfused atria (Bachem AG ; $10 \mathrm{nM}, \mathrm{n}=6$ ). Group 10 included ET-3 -perfused atria (Bachem AG; $10 \mathrm{nM}$, $100 \mathrm{nM}, \mathrm{n}=7$ each). Group 11 included s6C-perfused atria (Sigma-Aldrich, St. Louis, MO; $100 \mathrm{nM}, \mathrm{n}=7)$.

ET-1, ET-2, ET-3, or s6C was perfused into atria at 5 min before sample collection. Atria were pretreated with BQ123 or BQ788 15 min before sample collection and perfused simultaneously with ET-1 at 5 min before sample collection. 


\subsection{Acute infusion of ET-1 or ET-3 with and without NPR-A antagonist}

In order to evaluate the physiological role of ANP in ET-induced pressor effect, an increase in arterial blood pressure (ABP) in response to intravenous injection of ET-1 and ET-3 was compared in the absence and presence of natriuretic peptide receptor-A (NPR-A) antagonist, A71915. Male Sprague-Dawley rats, weighing 230-250 g, were anesthetized by intraperitoneal injection of a mixture of ketamine and xylazine $(9: 1,2 \mathrm{ml} / \mathrm{kg})$. Body temperature was maintained at $37^{\circ} \mathrm{C}$ using a heating pad. Following midline incision in the neck, the jugular vein and carotid artery were carefully dissected, cannulated with a polyethylene tube (PE-50), and secured with ligation. The cannulus in the jugular vein was connected to a peristaltic pump (Minipuls 2 Gilson, Villiers le Bel, France) for infusion of vehicle $(0.9 \% \mathrm{NaCl})$ or ET and the cannula in the carotid artery were connected to the pressure transducer (Statham $\mathrm{P} 23 \mathrm{Db})$. ABP and heart rate (HR) were recorded using a Power lab (ML-820, ADInstruments Pvt. Ltd.) via the pressure transducer. After stabilization for $5 \mathrm{~min}$, one $\mathrm{ml} / \mathrm{kg}$ of ET-1 or ET-1 solution, at a concentration of $0.1 \mathrm{nM}$ or $30 \mathrm{nM}$, respectively, was infused for $20 \mathrm{sec}$ through the jugular vein and ABP and HR were continuously recorded for $15 \mathrm{~min}$. After recovery of BP and HR to control level, $250 \mu \mathrm{l}$ of NPR-A receptor antagonist (Bachem AG; A71915, $3 \mu \mathrm{M}$ ) was injected at 5 min before ET1 or ET-3 injection followed by the infusion for $20 \mathrm{~min}$ at a rate of $100 \mu \mathrm{l} / \mathrm{min}$. ET-1 or ET-3 was injected in the presence of A71915 and BP and HR were continuously recorded ( $\mathrm{n}=5$ for each group).

\subsection{Radioimmunoassay of ANP}

The concentration of immunoreactive ANP in atrial perfusates and plasma was measured using specific radioimmuoassay (RIA) as described previously [5]. RIA was performed in 
Tris-acetate buffer $(0.1 \mathrm{M}, \mathrm{pH} 7.4)$ containing neomycin $(0.2 \%)$, ethylenediamine tetraacetic acid ( $1 \mathrm{mM})$, soybean trypsin inhibitor (50 benzoyl arginine ethyl ester units/ml), aprotinin (200 KIU/ml), phenylmethylsulfonylfluoride $(0.4 \mathrm{mg} \%)$, sodium azide $(0.02 \%)$ and BSA (1\%). Standard and samples were incubated with anti-ANP antibody and $\left[{ }^{125} \mathrm{I}\right]$-ANP for $24 \mathrm{~h}$ at $4^{\circ} \mathrm{C}$. Bound forms were separated from free forms using charcoal suspension for ANP in perfusate. RIA for ANP was done on the day of experiments and all samples in an experiment were analyzed in a single assay. The intra- and inter-assay coefficiency of variation were $6.3 \%(\mathrm{n}=9)$ and $7.8 \%(\mathrm{n}=11)$, respectively.

The secreted amount of ANP was expressed as ng ANP per min per $g$ of tissue wet weight. The molar concentration of ANP release was calculated as follows [3]:

ANP released $(\mu \mathrm{M})=\mathrm{ANP}(\mathrm{pg} / \mathrm{min} / \mathrm{g}) / \mathrm{ECF}$ translcation $(\mu \mathrm{l} / \mathrm{min} / \mathrm{g}) / 3060$

The denominator 3060 refers to the molecular mass for $\mathrm{ANP}_{(1-28)}(\mathrm{Da})$ since the ANP secreted was found to be mainly the processed ANP $[3,4]$.

\subsection{Measurement of ECF translocation}

The ECF translocated from atria was measured as described previously [3]. At the start of atrial perfusion, pericardial buffer solution contained $\left[{ }^{3} \mathrm{H}\right]$-inulin. Radioactivities in atrial perfusate and pericardial buffer solution were measured with a liquid scintillation counter and the amounts of ECF translocated through atrial wall were calculated as follows:

ECF translocation $(\mu \mathrm{l} / \mathrm{min} / \mathrm{g})=$ total radioactivity in perfusate $(\mathrm{cpm} / \mathrm{min}) /$ radioactivity in pericardial reservoir $(\mathrm{cpm} / \mu \mathrm{l}) /$ atrial wet weight $\mathrm{x} 1000$

\subsection{Statistical analysis}

The results were given as means \pm SEM. Statistical significance of differences was performed by one-way or two-way repeated measures analysis of variance followed by the Bonferroni 
test. The linear regression analysis was also used (Prism 5, GraphPad Software, Inc., La Jolla, CA). 


\section{Results}

\subsection{Effect of ET-1 on ANP secretion from isolated atria}

Figure 1 shows the effect of atrial distension on volume change (Fig. 1B), ANP secretion (Fig. 1C), and ECF translocation (Fig. 1D) in left atria of normal rats. By increasing atrial pressure from basal level $\left(0 \mathrm{cmH}_{2} \mathrm{O}\right)$ to $1,2,4$, or $6 \mathrm{cmH}_{2} \mathrm{O}$ for $2 \mathrm{~min}$, the atrium was distended and then, the atrial size was reduced after return of atrial pressure to basal level. Changes in atrial volume induced by atrial distension and reduction (DRV) were proportionately increased in response to atrial pressure (Fig. 1B). ET-1 tended to decrease atrial volume changes in response to increased atrial pressure without significance.

When atrial distension induced by increasing the pressure was reduced to the basal level, the secretion of ANP was significantly increased proportionately to DRV. ET-1 (10 nM) stimulated both basal and stretch-activated ANP secretion (Fig. 1C). We have already shown that the ANP secretion is regulated by two step-sequential mechanism, one is the release of ANP from atrial myocytes into the extracellular space and then the translocation of ECF with the released ANP into the atrial lumen by atrial contraction [3]. Therefore, the translocation of ECF using $\left[{ }^{3} \mathrm{H}\right]$-inulin clearance was measured simultaneously with the secretion of ANP. Increases in DRV also caused proportional increases in mechanically-stimulated ECF translocation, which were attenuated by ET-1 (Fig. 1D). Therefore, the stretch-activated ANP secretion from atria into the atrial lumen in relation to the translocation of ECF (ANP concentration in the interstitium) was increased. ET-1 augmented basal and stretch-activated ANP concentration (Fig. 1E).

\subsection{Effect of ET-1 on ANP secretion with and without ET receptor blocker}

Figure 2 shows the effect of $\mathrm{ET}_{\mathrm{A}}$ receptor blocker (BQ123) on DRV, ANP secretion and ECF 
translocation. BQ123 attenuated stretch-activated ANP secretion (Fig. 2C) but did not change basal ANP secretion and ECF translocation (Fig. 2D). Therefore, the ANP concentration in the interstitium was attenuated by BQ123 (Fig. 2E). However, ET $_{\mathrm{B}}$ receptor blocker (BQ788) had not significant effects on ANP secretion and ECF translocation (data not shown).

Figure 3A shows the relationships between atrial pressure, DRV, changes in mechanically-stimulated ECF translocation and stretch-activated ANP secretion with and without ET-1. When intra-atrial pressure was increased by 1, 2, 4, or $6 \mathrm{cmH}_{2} \mathrm{O}$, DRV were increased proportionately to pressure (Fig. 3Aa). DRV positively correlated with ANP secretion and ECF translocation (Fig. 3, Ab and c). So, there was a close correlation between ANP secretion and ECF translocation (Fig. 3Ad). The stretch-activated ANP secretion was markedly augmented without difference in DRV by ET-1. Therefore, the relationship between ANP secretion and ECF translocation shifted to the left and upward by ET-1 (Fig. 3Ad). The stretch-activated ANP secretion was markedly attenuated by BQ123. So, BQ123 caused the relationship between ANP secretion and ECF translocation to the right and downward (Fig. 3Ba). However, BQ788 did not cause any significant changes in ANP secretion and ECF translocation. Therefore, there was no shift the relationship between these parameters by BQ788 (Fig. 3Bb).

To compare quantitatively the stretch-activated ANP secretion among groups, the stretchactivated ANP secretion in terms of ECF translocation (i.e., the slope of linear regression) was calculated (Fig. 3C). ET-1 increased the ratio of changes in ANP secretion and ECF translocation (ANP/ECF) by a 4-fold $(1.68 \pm 0.10$ vs $0.37 \pm 0.03 \mathrm{ng} / \mu \mathrm{l}, \mathrm{p}<0.001)$. BQ123 alone attenuated ANP/ECF $(0.34 \pm 0.02$ vs $0.58 \pm 0.04 \mathrm{ng} / \mu \mathrm{l}, \mathrm{p}<0.05)$ and completely blocked ET-1-induced ANP/ECF (0.44 \pm 0.04 vs $0.34 \pm 0.02 \mathrm{ng} / \mu \mathrm{l})$. However, BQ788 did not affect ANP/ECF and ET-1-induced ANP/ECF. In low $\mathrm{Ca}^{2+}$ condition, basal and stretchactivated ANP secretions were markedly increased and ANP/ECF was higher than that in 
normal $\mathrm{Ca}^{2+}$ condition. ET-1-stimulated ANP secretion was abolished in low $\mathrm{Ca}^{2+}$ condition $(3.90 \pm 0.18$ vs $3.82 \pm 0.42 \mathrm{ng} / \mu \mathrm{l})($ Fig. 3C)

\subsection{Effect of ET-2, ET-3, and s6C on ANP secretion from isolated atria}

To compare ET-1 to ET-2, ET-3 and s6C on ANP secretion, ET-2, ET-3, or s6C was perfused. ET-2 at a dose of $10 \mathrm{nM}$ augmented stretch-activated ANP secretion and the relationship between these two parameters shifted to the left and upward (Fig. 4Aa). ET-3 at a dose of 10 $\mathrm{nM}$ and $100 \mathrm{nM}$ also augmented stretch-activated ANP secretion and the relationship between these two parameters shifted to the left and upward (Fig. 4Ab). s6C also shifted the relationship between these two parameters to the left and upward (Fig. 4Ab). As a results of direct comparison of ANP/ECF among ET family, the effect of $10 \mathrm{nM}$ ET-3 on ANP/ECF $(1.35 \pm 0.06 \mathrm{ng} / \mathrm{ml})$ was significantly lower than those of $10 \mathrm{nM} \mathrm{ET}-1(2.53 \pm 0.23 \mathrm{ng} / \mathrm{ml})$ and ET-2 $(2.21 \pm 0.10 \mathrm{ng} / \mathrm{ml})$. The effect of $100 \mathrm{nM} \mathrm{ET}-3$ on ANP/ECF $(1.95 \pm 0.12 \mathrm{ng} / \mathrm{ml})$ was significantly higher than that of $100 \mathrm{nM} \mathrm{s6C}(0.91 \pm 0.04 \mathrm{ng} / \mathrm{ml})$ (Fig. 4B).

\subsection{Acute infusion of ET-1 or ET-3 with and without NPR-A antagonist}

Figure 5A shows a representative tracing of changes in BP by ET-1 and ET-3 with and without NPR-A antagonist. MAP before ET-1 infusion in the absence or presence of A71915 infusion was not different (Fig. 5Ba). Acute injection of ET-1 (0.1 nM) caused an increased MAP by $27.5 \pm 2.43 \mathrm{mmHg}$ at $2 \mathrm{~min}$, which gradually decreased to control level. ET-1 in the presence of NPR-A receptor blocker increased by $36.9 \pm 3.09 \mathrm{mmHg}$ at $3 \mathrm{~min}$, which gradually decreased until 12 min after injection. An increased MAP by ET-1 with NPR-A receptor antagonist was significantly higher and its action was longer than that by ET-1 without NPR-A receptor antagonist (Fig. 5Bb). Acute injection of ET-3 (30 nM) caused an 
increased MAP by $10.50 \pm 1.82 \mathrm{mmHg}$ at $1 \mathrm{~min}$, which gradually decreased to control level. Similarly, ET-3 with NPR-A receptor antagonist caused an increased MAP by $18.13 \pm 1.95$ $\mathrm{mmHg}$ at $1 \mathrm{~min}$, which was higher than that by ET-3 alone (Fig. $5 \mathrm{Bc})$. 


\section{Discussion}

The present study shows that ET-1 stimulates basal and stretch-activated ANP secretions via $\mathrm{ET}_{\mathrm{A}}$ receptor and the order of secretagogue effect of ET family on ANP secretion was ET-1 $\geq$ ET-2 >> ET-3 > sC6. In vivo study showing an augmentation of high BP induced by ET-1 and ET-3 in the presence of NPR-A receptor blocker suggests that an increase in plasma ANP concentration by either ET-1 or ET-3 negatively inhibits the pressor effect of ET-1.

ET-1 is the main isoform of ET family which is synthesized in endothelial cells, muscular coat of arterial wall as well as in heart, kidney, and central nervous system. ET-1 raises BP, induces vascular and myocardial hypertrophy. The effects of ET family are reported to be different among isoforms. ET-1 is well known as a potent stimulator of ANP but, there are a few reports about the potency of secretagogue effect of ET family on ANP secretion. The aim of the present study was to compare the secretagogue effect of ET-1 on ANP secretion with ET-2, ET-3, and sarafotoxin in isolated perfused nonbeating atria. It is well-known that changes in atrial volume but not in pressure is an important stimulus of ANP secretion from isolated perfused atria $[4,5]$. In atrial model used in this study, changes in atrial volume (DRV) induced by changing atrial pressure stimulated ANP secretion with ECF translocation $[5,19,20]$. There were positive correlations among DRV, ANP secretion, and ECF translocation. The ET family did not affect DRV and ECF translocation. ET-1 (10 nM) stimulated both basal and stretch-activated ANP secretion from atrial myocytes via $\mathrm{ET}_{\mathrm{A}}$ receptor but not via $\mathrm{ET}_{\mathrm{B}}$ receptor. These results are consistent with other reports $[10,16,20$, 28]. $\mathrm{ET}_{\mathrm{A}}$ receptor antagonist but not $\mathrm{ET}_{\mathrm{B}}$ receptor antagonist itself suppressed stretchactivated ANP secretion without change in ECF translocation. It means that ET-1 may be endogenously secreted by atrial stretch and be partly involved in the stimulation of stretch- 
activated ANP secretion via $\mathrm{ET}_{\mathrm{A}}$ receptor as a paracrine fashion. Skvorak et al showing stretch-induced ANP secretion stimulated by ET-1 and suppressed by BQ-123 using isolated perfused atria suggest that the stretch-induced release of ANP is partially regulated by ET and that the ET is locally produced and constitutes a paracrine control system [28]. Our results confirmed their previous findings [28].

Among ET family, ET-2 is very similar to ET-1 and, ET-3 and sarafotoxin differ from ET-1 by six and seven amino acids, respectively. All ET family stimulated stretch-activated ANP secretion but the potency was different. ET-2 increased ANP/ECF similarly to ET-1 whereas ET-3 increased ANP/ECF but less than ET-1. The order of secretagogue effect of ET family on ANP secretion was ET-1 $\geq$ ET-2 >> ET-3 > s6C.

It has been reported that high plasma level of ET-1 in cardiac hypertrophy and pulmonary hypertension $[23,27]$ increased plasma ANP secretion due to augmentation of ET-1-induced ANP secretion from hypertrophied atria [20] and ventricle [30], and a decrease in metabolism [21]. The maintenance of high level of plasma ANP in cardiac hypertrophied rats can be explained as a compensatory mechanism to reduce cardiac workload by a decreased ECF volume and vasodilation. In the present study, we tested acute compensation of ANP on ETinduced pressor effect in anesthetized rats. ET-1 increased MAP more than ET-3 and pretreatment with a NPR-A receptor antagonist potentiated the MAP response to ET-1 and ET-3 and increased the duration of action. These data suggest that elevations in plasma ANP concentration in response to ET-1 or ET-3 limits the blood pressure response to ET-1. We did not measure plasma ANP level because frequent blood collection for the measurement of plasma ANP may interfere or mask the compensatory effect of endogenous ANP. In addition, it has been reported that an infusion of ET-1 results in an increase in plasma ANP levels, which may also contribute to ET-1-induced natriuresis [24]. Taken together, ET potentially interacts with ANP in the regulation of BP and sodium balance. 
Therefore, we suggest that the order of secretagogue effect of ET family on ANP secretion was ET-1 $\geq$ ET-2 >> ET-3 > s6C and ANP induced by ET participates in the homeostatic regulation of BP by inhibiting the pressor effect of ET-1.

\section{Acknowledgments}

This work was supported by the National Research Foundation of Korea (NRF) grant funded 
by the Korea government (MSIP) (No 2008-0062279) and partly by the National Natural Science Foundation of China (No. 81160034).

\section{Figure legends}

Figure 1. Changes in atrial pressure (A), distension-and-reduction volume (B, DRV), ANP 
secretion (C), ECF translocation (D), and ANP concentration (conc, E) by endothelin-1 (ET-1) from left atria. Atrial volume change (DRV) was increased by the elevation of intra-atrial pressure. A step wise increase in DRV resulted in proportional increases in ANP secretion and concomitant ECF translocation. The stretch-activated ANP secretion and concentration were significantly higher in ET-1 treated atria than those in control atria. Values are the means $\pm \operatorname{SEM}(n=7-8) .{ }^{*}$, Significantly different from control group, $P<0.05 ; * * P<0.01$.

Figure 2. Changes in atrial pressure (A), DRV (B), stretch-activated ANP secretion (C), mechanically-stimulated ECF translocation (D), and ANP concentration (E) by $\mathrm{ET}_{\mathrm{A}}$ receptor antagonist (BQ123) from left atria. The stretch-activated ANP secretion and concentration were significantly lower in BQ123-treated atria than those in control atria. Values are the means \pm SEM ( $n=7$ for each group). ${ }^{*}$, Significantly different from control group, $P<0.05 ; * * P<0.01$.

Figure 3. (A) Relationships between atrial pressure, DRV, mechanically-stimulated ECF translocation, and stretch-activated ANP secretion in left atria treated with vehicle and ET-1. (B) Relationships between mechanically-stimulated ECF translocation, and stretch-activated ANP secretion in left atria treated with BQ123 and BQ788. In ET-1treated atria, the relationships between ANP secretion and DRV, and ANP secretion and ECF translocation (Ad) shifted to the right and upward. In BQ123-treated atria, the relationships between ANP secretion and ECF translocation shifted to the left and downward (Ba). BQ788 did not cause any significant changes in ANP secretion and ECF translocation $(\mathrm{Bb}) .(\mathrm{C})$ Comparison of stretch-activated ANP secretion in terms of ECF translocation by ET-1 in the presence of BQ123, BQ788, and low $\mathrm{Ca}^{2+}$ condition. An increase in stretch-activated ANP secretion in terms of ECF translocation was blocked by the pretreatment with BQ123 but not with BQ788. ET-1-stimulated ANP secretion 
was also abolished in low $\mathrm{Ca}^{2+}$ condition. Values are the means $\pm \operatorname{SEM}(\mathrm{n}=6-10) .{ }^{*}$, Significantly different from control group, $P<0.05$, ** $P<0.01$, *** $P<0.005$; \#\#, Significantly different from BQ788-treated atria, $P<0.01$.

Figure 4. (A) Relationships between mechanically-stimulated ECF translocation and stretchactivated ANP secretion in left atria treated with ET-2, ET-3, and s6C. (B) Comparison of stretch-activated ANP secretion in terms of ECF translocation by ET-1 with ET-2, ET-3, and s6C. Values are the means \pm SEM $(n=6-7) . *$, Significantly different from control group, $P<0.05$, ** $P<0.01$.

Figure 5. (A) Representative tracing of change in arterial blood pressure (ABP) by ET-1 (0.1 $\mathrm{nM})$ and ET-3 (30 nM) with and without natriuretic peptide receptor-A blocker (A71915). (B) Mean arterial pressure (MAP) before ET-1 infusion in the absence or presence of A71915 (a) and changes in mean ABP by ET-1 (b) and ET-3 (c) with and without A71915. Values are the means $\pm \operatorname{SEM}(n=5) . *$, Significantly different from ET alone group, $P<0.05$.

\section{References}

[1] Barton M. Reversal of proteinuric renal disease and the emerging role of endothelin. 
Nature clinical practice Nephrology. 2008;4:490-501.

[2] Barton M, Yanagisawa M. Endothelin: 20 years from discovery to therapy. Can J Physiol Pharmacol. 2008;86:485-98.

[3] Cho KW, Kim SH, Hwang YH, Seul KH. Extracellular fluid translocation in perfused rabbit atria: implication in control of atrial natriuretic peptide secretion. J Physiol. $1993 ; 468: 591-607$.

[4] Cho KW, Lee SJ, Wen JF, Kim SH, Seul KH, Lee HS. Mechanical control of extracellular space in rabbit atria: an intimate modulator of the translocation of extracellular fluid and released atrial natriuretic peptide. Exp Physiol. 2002;87:185-94.

[5] Cho KW, Seul KH, Ryu H, Kim SH, Koh GY. Characteristics of distension-induced release of immunoreactive atrial natriuretic peptide in isolated perfused rabbit atria. Regul Peptides. 1988;22:333-45.

[6] Chou SY, Porush JG. Renal actions of endothelin-1 and endothelin-3: interactions with the prostaglandin system and nitric oxide. Am J Kidney Dis. 1995;26:116-23.

[7] de Bold AJ. Thirty years of research on atrial natriuretic factor: historical background and emerging concepts. Can J Physiol Pharmacol. 2011;89:527-31.

[8] de Bold AJ, Borenstein HB, Veress AT, Sonnenberg H. A rapid and potent natriuretic response to intravenous injection of atrial myocardial extract in rats. Life Sci. 1981;28:89-94.

[9] Dietz JR. Release of natriuretic factor from rat heart-lung preparation by atrial distension. Am J Physiol. 1984;247:R1093-6.

[10] Dietz JR. Mechanisms of atrial natriuretic peptide secretion from the atrium. Cardiovasc Res. 2005;68:8-17.

[11] Fukuda Y, Hirata Y, Taketani S, Kojima T, Oikawa S, Nakazato H, et al. Endothelin stimulates accumulations of cellular atrial natriuretic peptide and its messenger RNA in 
rat cardiocytes. Biochem Biophys Res Commun. 1989;164:1431-6.

[12] Fukuda Y, Hirata Y, Yoshimi H, Kojima T, Kobayashi Y, Yanagisawa M, et al. Endothelin is a potent secretagogue for atrial natriuretic peptide in cultured rat atrial myocytes. Biochem Biophys Res Commun. 1988;155:167-72.

[13] Garcia R, Lachance D, Thibault G. Positive inotropic action, natriuresis and atrial natriuretic factor release induced by endothelin in the conscious rat. J Hyper. 1990;8:725-31.

[14] Gardiner SM, Compton AM, Bennett T. Regional haemodynamic effects of endothelin-1 and endothelin-3 in conscious Long Evans and Brattleboro rats. Brit J Pharmacol. 1990;99:107-12.

[15] Genest J, Cantin M. The atrial natriuretic factor: its physiology and biochemistry. Rev Physiol Biochem Pharmacol. 1988;110:1-145.

[16] Hu JR, Berninger UG, Lang RE. Endothelin stimulates atrial natriuretic peptide (ANP) release from rat atria. Eur J Pharmacol. 1988;158:177-8.

[17] Ishikawa T, Yanagisawa M, Kimura S, Goto K, Masaki T. Positive chronotropic effects of endothelin, a novel endothelium-derived vasoconstrictor peptide. Pflugers Archiv : Eur J Physiol. 1988;413:108-10.

[18] Ishikawa T, Yanagisawa M, Kimura S, Goto K, Masaki T. Positive inotropic action of novel vasoconstrictor peptide endothelin on guinea pig atria. Am J Physiol. 1988;255:H970-3.

[19] Kim SH, Cho KW, Chang SH, Kim SZ, Chae SW. Glibenclamide suppresses stretchactivated ANP secretion: involvements of $\mathrm{K}+\mathrm{ATP}$ channels and L-type $\mathrm{Ca}^{2+}$ channel modulation. Pflugers Arch. 1997;434:362-72.

[20] Kim SH, Lee KS, Kim YA, Seul KH, Kim SZ, Cho KW. Accentuation of ANP secretion to endothelin-1 in hypertrophied atria. Regul Peptides. 2001;102:21-9. 
[21] Kim SZ, Cho KW, Kim SH. Modulation of endocardial natriuretic peptide receptors in right ventricular hypertrophy. Am J Physiol. 1999;277:H2280-9.

[22] Lang RE, Tholken H, Ganten D, Luft FC, Ruskoaho H, Unger T. Atrial natriuretic factor--a circulating hormone stimulated by volume loading. Nature. 1985;314:264-6.

[23] Miyauchi T, Yorikane R, Sakai S, Sakurai T, Okada M, Nishikibe M, et al. Contribution of endogenous endothelin-1 to the progression of cardiopulmonary alterations in rats with monocrotaline-induced pulmonary hypertension. Circ Res. 1993;73:887-97.

[24] Munger KA, Sugiura M, Takahashi K, Inagami T, Badr KF. A role for atrial natriuretic peptide in endothelin-induced natriuresis. J Am Soc Nephrol. 1991;1:1278-83.

[25] Neuser D, Knorr A, Stasch JP, Kazda S. Mitogenic activity of endothelin-1 and -3 on vascular smooth muscle cells is inhibited by atrial natriuretic peptides. Artery. $1990 ; 17: 311-24$

[26] Ohman KP, Hoffman A, Keiser HR. Endothelin-induced vasoconstriction and release of atrial natriuretic peptides in the rat. Acta Physiol Scand. 1990;138:549-56.

[27] Prie S, Leung TK, Cernacek P, Ryan JW, Dupuis J. The orally active ET(A) receptor antagonist (+)-(S)-2-(4,6-dimethoxy-pyrimidin-2-yloxy)-3-methoxy-3,3-diphe nylpropionic acid (LU 135252) prevents the development of pulmonary hypertension and endothelial metabolic dysfunction in monocrotaline-treated rats. J Pharmacol Exp Ther. 1997;282:1312-8.

[28] Skvorak JP, Nazian SJ, Dietz JR. Endothelin acts as a paracrine regulator of stretchinduced atrial natriuretic peptide release. Am J Physiol. 1995;269:R1093-8.

[29] Smith FG, Sato T, Varille VA, Robillard JE. Atrial natriuretic factor during fetal and postnatal life: a review. J Develop Physiol. 1989;12:55-62.

[30] Thibault G, Nemer M, Drouin J, Lavigne JP, Ding J, Charbonneau C, et al. Ventricles as a major site of atrial natriuretic factor synthesis and release in cardiomyopathic hamsters 
with heart failure. Circ Res. 1989;65:71-82.

[31] Yanagisawa M, Masaki T. Endothelin, a novel endothelium-derived peptide.

Pharmacological activities, regulation and possible roles in cardiovascular control. Biochem Pharmacol. 1989;38:1877-83. 

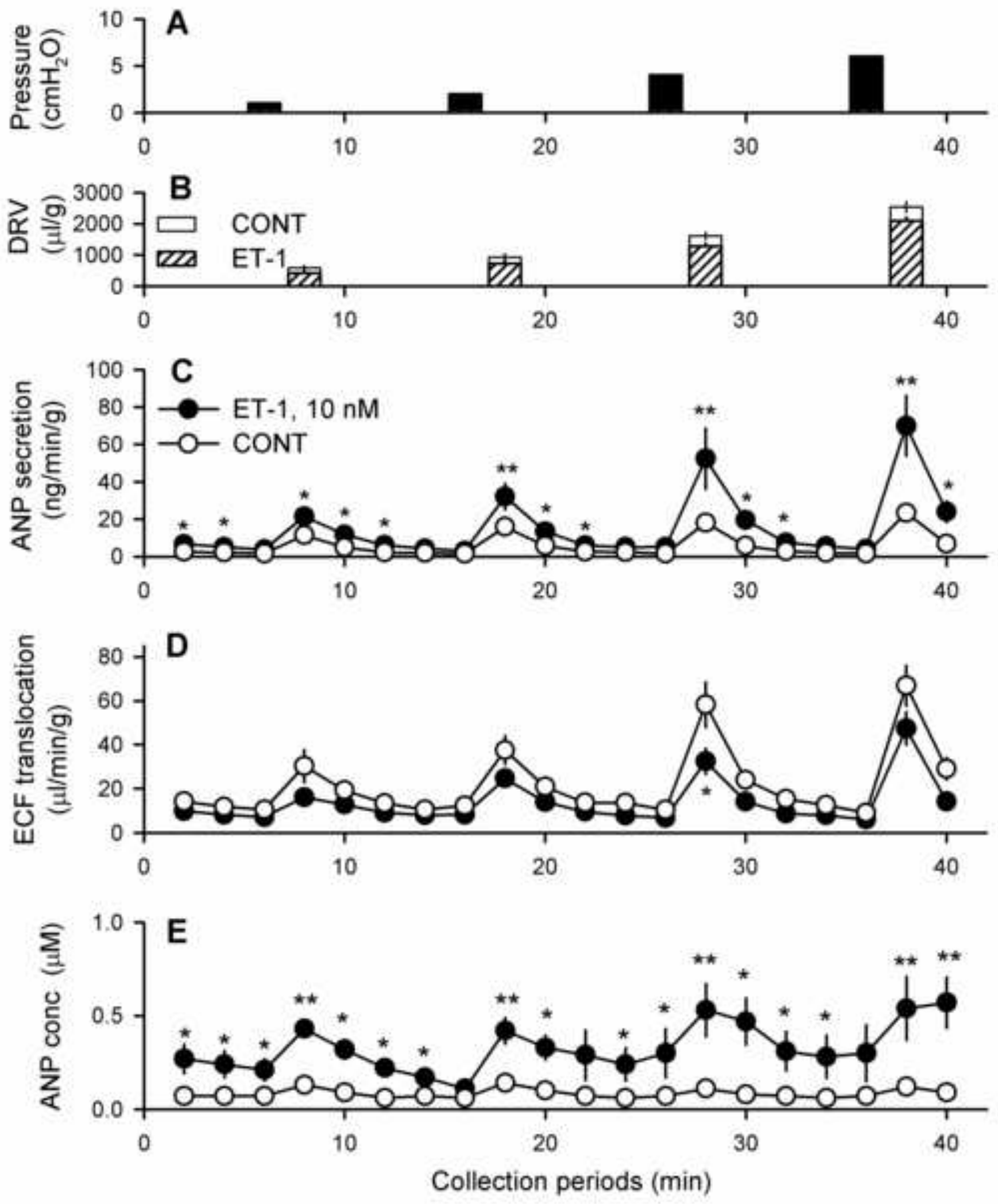

Fig. 1 
Figure 2
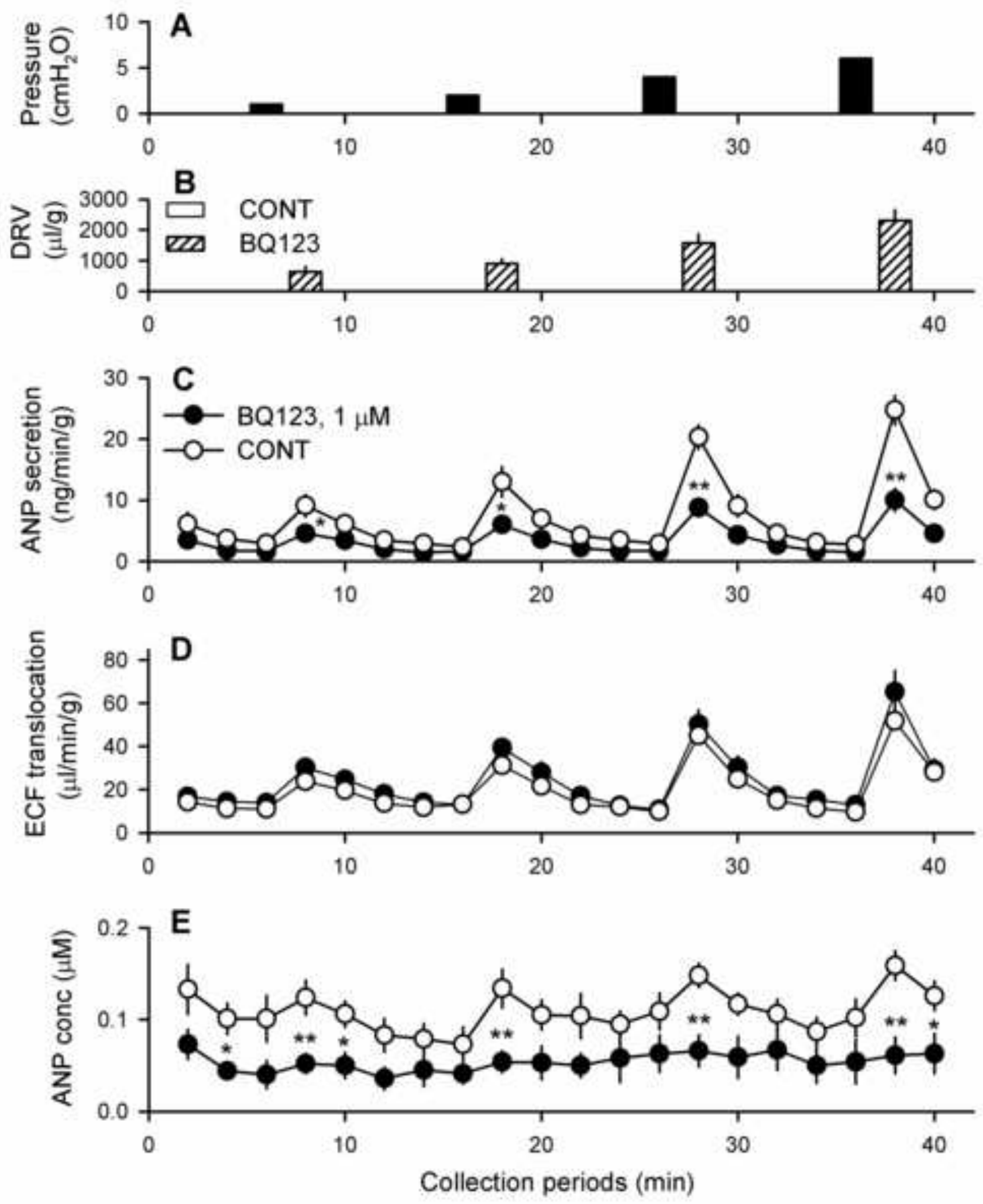

Fig. 2 
A ET-1
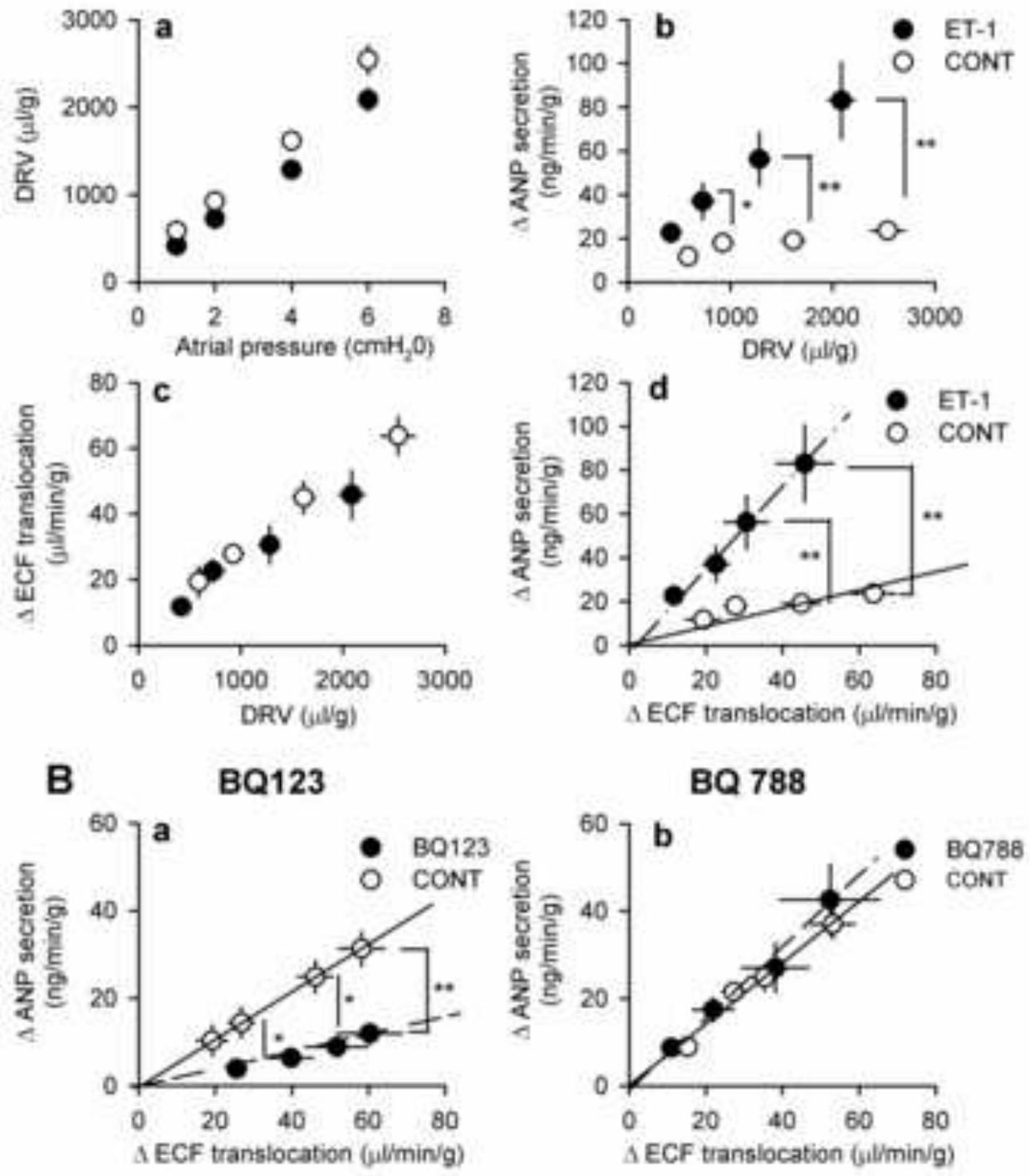

C

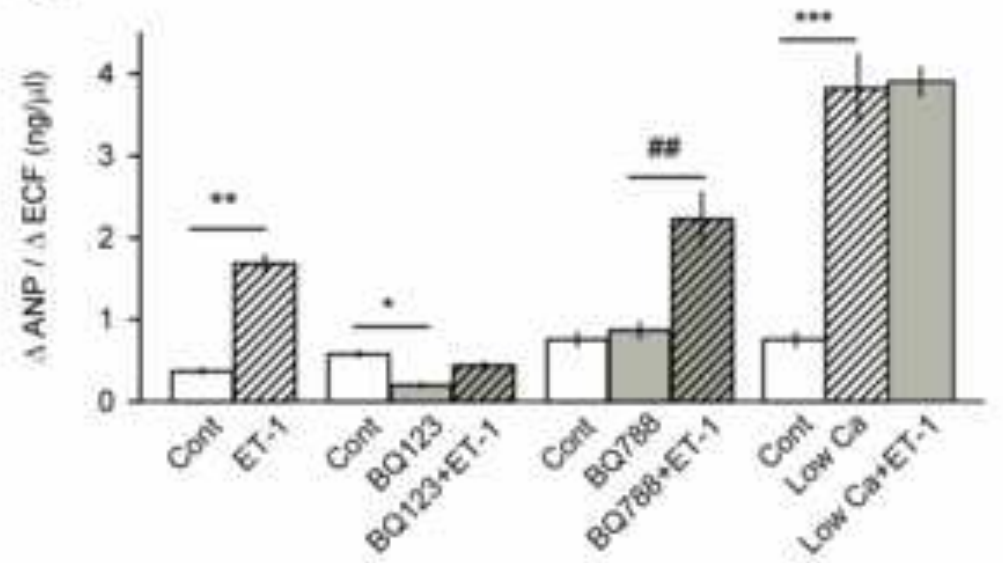

Fig. 3 

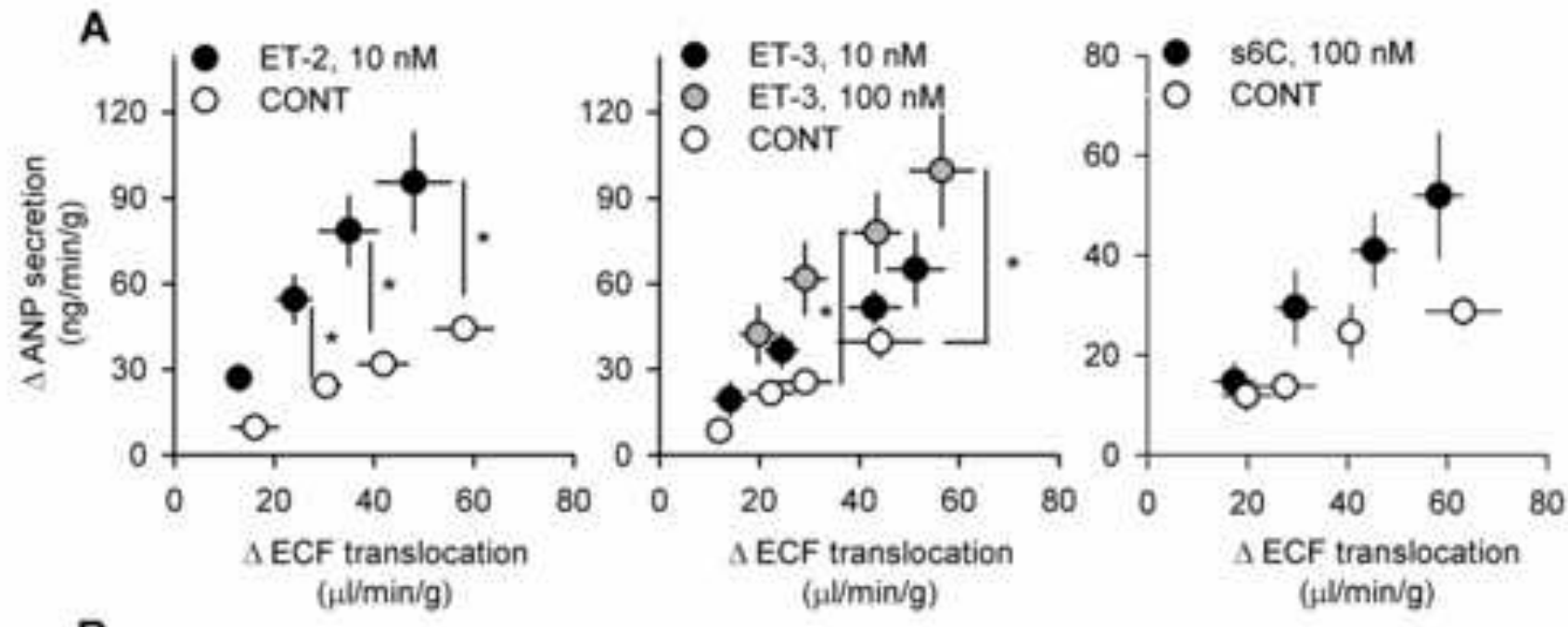

\section{B}

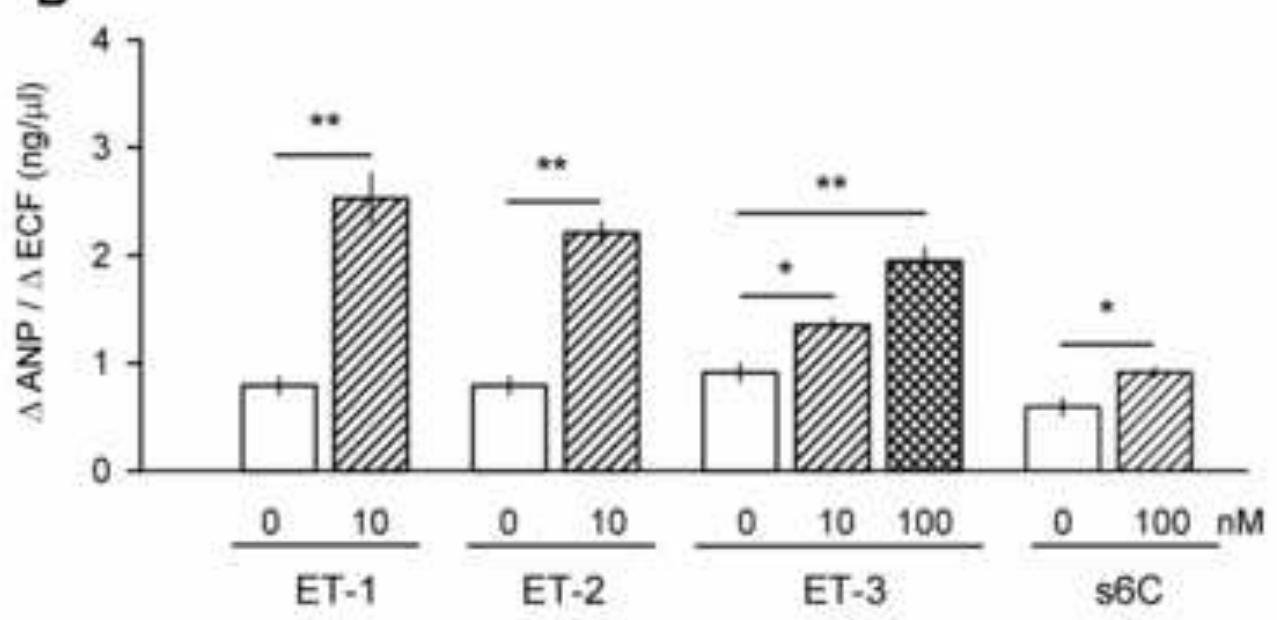

Fig. 4 
A

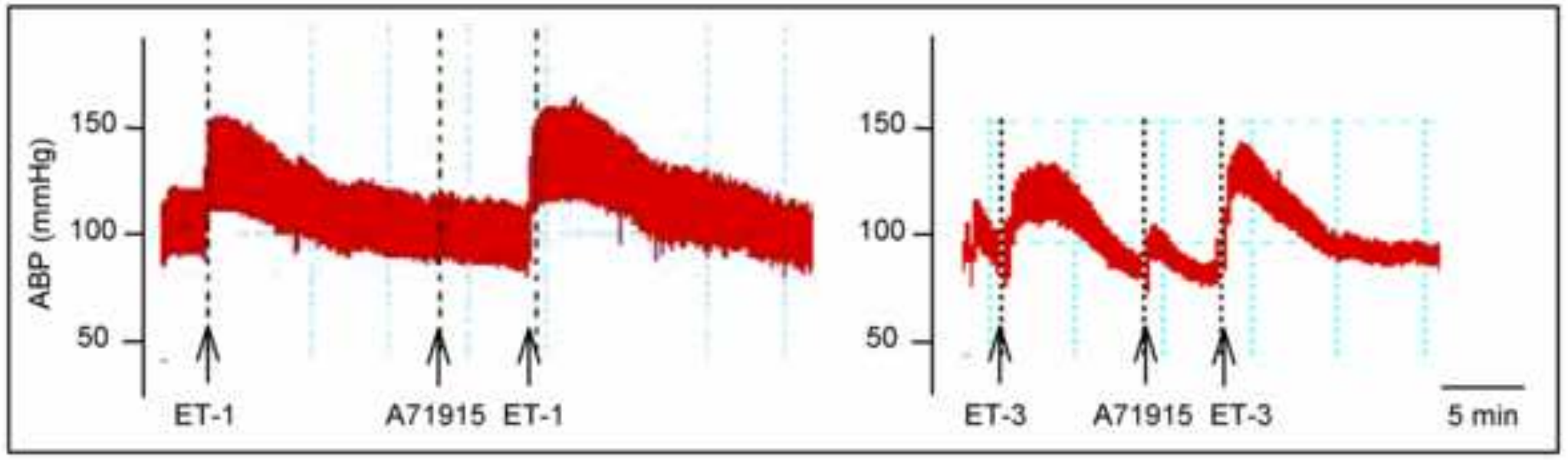

B
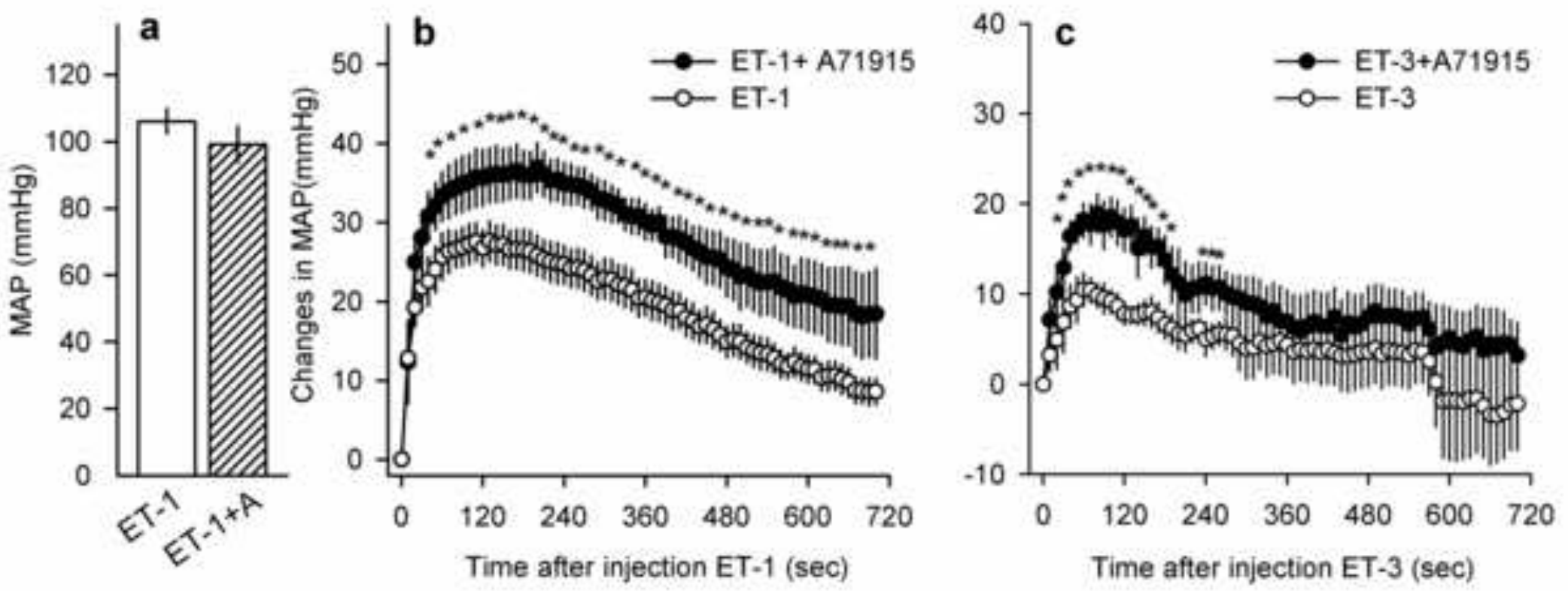

Fig. 5 